\title{
TELEVISÃO E INFÂNCIA
}

Mais de cem pessoas reunidas em São Paulo, no Seminário Televisão e Infância, promovido pela TV Cultura e Instituto Goethe nos dias 3 e 4 de junho de 1995, discutiram e analisaram os diversos aspectos que envolvem o relacionamento da criança com a TV. Pesquisadores, educadores, psicólogos, publicitários, cineastas, produtores, programadores e jornalistas, entre outros foram convidados a participar desta discussão que envolve a todos, como cidadãos e profissionais.

No documento final que agora apresentamos, foram consignadas todas as preocupações e sugestões que surgiram durante o Seminário. É uma primeira abordagem da questão, hoje na pauta de todo encontro internacional que fale de televisão. É também ponto de partida para um trabalho articulado em defesa de uma televisão de qualidade, não só para a criança, mas para a sociedade em geral.

O documento final, pela própria natureza do Seminário que o gerou, não é conclusivo. Alinha tanto imperativos de ação quanto objetivos desejados. Representa o primeiro passo de uma reflexão para a ação e uma tomada de consciência da seriedade do compromisso que devemos assumir.

\section{TEMAS EM DISCUSSÃO}

Muitas questões foram levantadas durante os dois dias de seminário. Foram alertas e preocupações legítimas, que provaram a necessidade de mais pesquisas e debates em torno do assunto. Aqui fica registrado um resumo desta ordem de idéias que permeou as discussões.

É preciso pensar sobre a televisão que queremos para nós e nossos filhos. Pode ser a televisão um instrumento moderador de comportamento sem cair na tirania da censura? Pode-se pensar em uma programação ideal sem cair em utopias? As emissoras seriam capazes de produzir uma televisão que respeite o público e seus interesses e não exclusivamente seus próprios interesses e os dos anunciantes? O público tem capacidade de dizer não? Então por que não diz? Qual o papel dos pais? O que é um bom programa infantil? A audiência é um atestado para este julgamento? Por que a violência atrai tanto? Violência gera violência? Quais os critérios de avaliação? As crianças têm recebido aquilo que querem? Que tipo de programas elas merecem? São as produções caras as melhores? Onde buscar recursos para produções necessariamente caras?

Em meio a tantas perguntas foi lembrado que estamos preparando crianças pa-

\section{OS AUTORES}

Beth Carmona

Diretora de Programação da TV Cultura, São Paulo.

Luiz Fernando Santoro

Professor Doutor do Departamento de Jornalismo e Editoração da ECA/USP.

Teresa Otondo

Coordenadora do Departamento de Documentário da TV Cultura, São Paulo.

Márcia Régis

Produtora da TV Cultura, São Paulo.

1. Relatório final do Seminário "Televisão e Infância", realizado pela TV Cultura e Instituto Goethe, de São Paulo, nos dias 3 e 4 de junho de 1995. 
ra viver em um mundo que nós mesmos não sabemos como será, e por isso é muito importante dar-lhes hoje critérios e parâmetros de comportamento para que possam, amanhã, fazer suas escolhas e tomar suas decisões de maneira livre, responsável e consciente.

Foi lembrado que, ainda que a televisão reflita a sociedade em que vivemos, ela não se faz sozinha, e os fazedores de TV e programas são ou deveriam ser responsáveis pelo que produzem. Assim como os telespectadores devem ser responsáveis pelo que assistem e, enquanto cidadãos, têm o direito de ser respeitados e o dever de protestar.

Foi visto que os índices de audiência medem o que as pessoas estão vendo dentro de um leque conhecido de opções, mas não medem como estão vendo.

Qual o grau real de interesse, de afinidade com o programa, principalmente quando se trata do público infantil?

Foi apontado que talvez faltem canais apropriados para que o telespectador se manifeste. Foi lembrado que existem os jornais, as cartas de leitores e o Código de Ética da ABERT (Associação Brasileira das Emissoras de Rádio e TV). Existem também o Estatuto do Menor e do Adolescente e a própria Constituição (artigo 221), leis que estão aí para serem cumpridas. É só o cidadão exigir. Temos também a Convenção dos Direitos da Criança (ONU 89) e a Carta do Rio.

Ainda, em âmbito internacional, batalham pela melhoria da programação infantil a Fundação Prix Jeunesse, a WATCH (World Alliance of Television for Children), a CTW (Children's Television Workshop), a Australian Children's Television
Foundation, o European Children's Television Center, a Philippine Children's Television Foundation e o Unicef, entre outros.

Existem ainda grupos de pressão como os americanos Children's Now e o Children's Act. Sem esquecer a Conferência de Cúpula sobre Televisão Infantil, realizada em Melbourne, Austrália, em março de 95 . Mais de 400 representantes do mundo inteiro discutiram, durante quatro dias, da violência à audiência, do papel do Estado às formas de financiamento $e$ de sustentação das TVs públicas, dos critérios de produção de bons programas infantis às dificuldades da produção independente.

Foi lembrado, finalmente, que exemplos positivos de bons programas para crianças, como os produzidos e exibidos pela TV Cultura de São Paulo, devem ser imitados, preservados e amparados.

Das conclusões sairão as recomendações que poderão integrar o Estatuto para a Televisão Infantil atualmente em discussão na Europa, que deverá ter vigência internacional.

\section{RECOMENDAÇÕES}

1. Considerando que a criança vê televisão mais do que os adultos - e vê tudo o que há na TV, não somente os programas infantis, inclusive em horários noturnos - , recomendamos:

* Estabelecer e respeitar padrões éticos que devem presidir toda a programação das emissoras. Especial atenção deve ser dada às chamadas dos programas da noite, feitas em horário destinado às crianças. $\mathrm{O}$ mesmo se refere ao jornalismo, ao recurso à violência excessiva e gratuita, ao sensacionalismo, a fatos e cenas fora de contexto. 
* Estabelecer claras regras do jogo, iguais para todas as emissoras, sem que seja necessário recorrer a um colégio de censores ou equivalente.

* Os critérios de produção de programas devem atender realmente às necessidades $\mathrm{e}$ anseios da criança (e, por que não, do público em geral) e não exclusivamente interesses particulares e comerciais.

* Estimular a realização de pesquisas sobre o que as crianças pensam da televisão, o que elas querem da TV, por que escolhem programas que pais e educadores acham incovenientes para elas. Enfim, ouvir a criança. * Investigar sobre o modo como as crianças lidam com o terror e o medo, apresentados em programas de ficção; a violência no jornalismo e a agressividade nos desenhos animados.

* Investir na pluralidade de linguagens, riqueza e variedade de gêneros e conteúdos da programação destinada ao público infantil. Investir em programas voltados para diferentes faixas etárias e de desenvolvimento das crianças.

* Desenvolver mecanismos de captação de recursos financeiros que garantam a produção e exibição de programas de qualidade para as crianças.

* Lembrar que as crianças aprendem a se situar no mundo vendo programas que exploram situações de vida, mas que não é preciso mostrar tudo para dar-lhes um conhecimento correto do mundo real.

* As emissoras, os programadores e os produtores devem se perguntar sempre: estou servindo à criança? Que contribuição traz este programa para a audiência infantil? Quais os melhores horários para as crianças? * Rejeitar a exploração comercial da criança na televisão e pela televisão.

* Criar programas para formar cidadãos respeitados e respeitadores, principalmente em momentos críticos para as relações civis como as atuais.

* Respeitar a criança, seus direitos, sua inteligência e sua sensibilidade.

2. Considerando que pais e professores lidam hoje com a criança televisiva e multimídia, cujas imagens, referenciais e linguagem vêm da televisão, recomendamos:

* Investir na preparação dos educadores para lidar com a linguagem audiovisual em sala de aula. Incorporar a televisão ao currículo.

* Pais e escola devem desenvolver maneiras de dialogar com as crianças a respeito dos programas a que assistem e às horas dedicadas à televisão.

* Fixar com as próprias crianças limites ao consumo de TV. É positivo e elas aceitam.

* Lembrar que a televisão não substitui pais ausentes ou negligentes e que a criança deixada sozinha fará suas escolhas sozinha.

* Incentivar pesquisas qualitativas sobre os papéis da televisão no campo da educação e sobre o uso da televisão pelos educadores. Não esquecer de integrar o rádio aos projetos educativos.

* Pensar a televisão como instrumento de educação permanente e continuada. Entender a TV como meio democrático de acesso à informação. Quase todos os lares têm aparelho de TV, porém nem todas as crianças freqüentam a escola.

* Lembrar que as crianças se envolvem com os programas de televisão de modo diferente do que os adultos acham que deveria ser.

* Lembrar que as crianças não vêem a televisão como uma sala de aula e, por isso, os programas que repetem esse esquema nem sempre funcionam. Certos contéudos curriculares não se aprendem só assistindo. É preciso acompanhamento pessoal. 
* Investir em profissionais especializados no trato da criança e da linguagem audiovisual.

* Lembrar que, mais do que o terror - que fascina tanto adultos quanto crianças -, o que as crianças mais temem é o imprevisível. A tensão e os excessos fazem mais mal do que a violência em si. O medo pode ser combatido ou controlado em uma ficção bem feita, que não use os recursos gratuitamente.

* Desenvolver nas crianças o olhar crítico frente à TV, para que deixem de ser espectadores passivos.

* Perguntar sempre: quem educa, como educa, para que sociedade estamos educando? Quais os critérios que devem nortear a produção de programas para crianças? Pais e educadores, enquanto telespectadores, devem estar sempre atentos a estas questões.

3. Considerando as dimensões continentais do Brasil, a diversidade, a pluralidade e as diferenças sociais e econômicas do país e sua população, recomendamos:

* Valorizar os aspectos regionais e essenciais de nossa cultura.

* Lutar pela representação das minorias, dos excluídos e dos deficientes, como componentes integrantes da programação e dos programas, evitando-se a segregação provocada por programas específicos sobre ou para esses setores da sociedade. Ou seja, incorporá-los nos contextos de programação ou programas.

* Buscar um equilíbrio representativo de nossa cultura neste mundo globalizado que preserve nossos valores regionais, nacionais e universais.
* Incentivar a realização de pesquisas qualitativas sobre o papel e uso da televisão no campo da cultura e da educação.

* Pensar a televisão como agente multiplicador de cultura.

* Refletir sobre a questão da identidade cultural, sobretudo na dramaturgia hoje concentrada no eixo Rio-São Paulo.

* Perguntar sempre: como respeitar e representar todas as diferenças, as minorias, as exclusões nos programas de TV?

* Incentivar a produção regional e sua circulação.

* Analisar as relações positivas e/ou negativas dos anunciantes com os programas.

* Buscar fontes e mecanismos de financiamento que garantam a produção de bons programas.

* Buscar formas de financiar e difundir pesquisas acadêmicas sobre televisão, criança e educação.

* Sensibilizar os meios de comunicação, a sociedade civil e o próprio Governo para a necessidade de uma ação continuada e estável em favor da educação e da cultura.

* Integrar os resultados deste seminário ao processo da Cadeia da Solidariedade, criada a partir da Declaração do Rio, firmada entre redes de TV líderes nos países da América do Sul e Caribe.

* Pleitear a integração das TVs Educativas

à Cadeia da Solidariedade pela contribuição específica ou potencial para o desenvolvimento de um conceito mais objetivo de TV para e pela criança.

* Encaminhar a organismos internacionais, via Unicef-Brasil, os resultados deste Seminário. 